\title{
Prevalence of At-Risk Under-Fives and Socio-Demographic Factors Affecting Them- A Cross-Sectional Observational Study
}

\author{
Prawin Chandra ${ }^{1}$, Kashif Shahnawaz ${ }^{2}$ \\ ${ }^{1}$ Department of Community Medicine, KMC, Katihar, Bihar, India. \\ ${ }^{2}$ Department of Community Medicine, GMC, Bettiah, Bihar, India.
}

\section{ABSTRACT}

\section{BACKGROUND}

Health status of children is an important and sensitive indicator of overall health of entire community. Majority of the illnesses in under-five children can be prevented through available measures. Childhood mortality is distributed in an extremely uneven manner, not only between the regions and countries but also within countries. High child mortality in India is due to multiple factors and their interactions. These determinants include social, economic, biological and demographic factors. Globally, the four major causes of mortality in under-five children are pneumonia, diarrhoeal diseases, pre-term birth complications, and birth asphyxia.

\section{METHODS}

A cross-sectional observational study was conducted in Urban Training Health Centre of Katihar medical college, Katihar, Bihar, for 2 months from Feb-2018 to April-2018. Selection of children was done by simple random sampling. Three hundred under five children were selected from the field area to identify ten risk factors. A pre-designed, pre-tested study schedule was used to collect data in which both open and close ended questions were included. Privacy and confidentiality were maintained for mothers of under-five children under present study. Anthropometric and clinical examinations of these children were performed to assess the risk factors under study. Shakir's Tape was used to measure mid-arm circumference and Salter's scale for weight. All data were collected and analysed using Microsoft Excel and Epi Info software 3.4.3. Results were calculated using percentages.

\section{RESULTS}

In our present study, thirty percent mothers were illiterate. Most mothers (64\%) were housewives. Two-thirds of these children belonged to lower class and $28.6 \%$ to upper class families. Nearly $70 \%$ children suffered from respiratory infections in the last one year. Acute respiratory tract infections were more common than gastrointestinal infections. Severe malnutrition was observed in $16 \%$ children. About $50 \%$ children were malnourished.

\section{CONCLUSIONS}

Health workers, especially in rural areas should be trained properly, so that they can identify risk factors for under-five children. There should be special provisions of health care facilities for under-five children. Necessary information, education and communication campaigns are needed to decrease infant and under-five morbidity and mortality. It is recommended that there is an urgent need and scope for operationalization of 'at-risk' under-five children through enhancement of staff competence and providing necessary logistic support.

\section{KEY WORDS}

Factors, Prevalence, Under-Five Children
Corresponding Author: Dr. Kashif Shahnawaz, Associate Professor, Department of Community Medicine, Government Medical College, Bettiah, Bihar, India.

E-mail: kashif.shahnawaz98@gmail.com

DOI: 10.14260/jemds/2020/77

Financial or Other Competing Interests: None.

How to Cite This Article:

Chandra P, Shahnawaz K. Prevalence of atrisk under-fives and socio-demographic factors affecting them- a cross-sectional observational study. J. Evolution Med. Dent. Sci.2020;9(06):339-342, 10.14260/jemds/2020/77 DOI:

Submission 03-10-2019,

Peer Review 16-01-2020,

Acceptance 24-01-2020,

Published 10-02-2020. 


\section{BACKGROUND}

Under-five children are about $14 \%$ of the total population. The health status of these children is an important and sensitive indicator of overall health of entire community. The Global Burden of Diseases 2015 (GBD-2015) found that the worldwide mortality figure among children $<5$ years of age dropped from 16.39 million in 1970 to 12.1 million in 1990 and 5.8 million in 2015 - a decrease that surpassed predictions. About one-thirds of deaths among children $<5$ years old occurred in Southern Asia and almost one half in Sub-Saharan Africa. ${ }^{1}$ Majority of the illnesses in under-five children can be prevented through available measures. "Atrisk" group is a group of individuals having the frequency of risk factors more than other groups. ${ }^{2}$ Due to limited resources all these at risk group of children cannot be given equal attention. So, these 'at-risk' groups should be identified properly, so that we can deliver them efficient paediatric services, because these children contributes largely to perinatal, neonatal, and infant mortality. ${ }^{3}$

Childhood mortality is distributed in an extremely uneven manner, not only between the regions and countries but also within countries. Socio-economic inequities and gender, to a large degree, determine which children live and which die. There is inequity in child health, which reflects in terms of under-five mortality in the world. The under-five mortality rate is 7,88 , and 120 in the industrialized, developing, and poor countries respectively. The under-five mortality rates in the developing countries are significantly higher among poorest quintile than the richest quintile of the populations. In India, the under-five mortality rates including infant, neonatal, and child mortality rates, started decling since the late 1970s and until 1993 the decline was substantial. High child mortality in India is due to multiple factors and their interactions. These determinants include social, economic, biological and demographic factors.

Globally, the four major causes of mortality in under-five children are pneumonia, diarrhoeal diseases, pre-term birth complications, and birth asphyxia. In developing countries almost $20 \%$ of the neonates develop sepsis. ${ }^{4}$ Klebsiella pneumonia and staphylococcus aureus are the most frequently isolated pathogens in septicemia. ${ }^{5}$ In India, acute diarrheal disease is one of the major consequences of not only water pollution but also of the failure of proper management of sewage in both cities and rural areas. The median diarrheal incidence rate ranges from 1.0 to 4.7 episodes per child per year. About 3 million deaths globally are associated with diarrhoea. India alone account for one third of these deaths. Around $65 \%$ of these deaths are due to dehydration, $20-35 \%$ due to persistent diarrhoea and remaining $15 \%$ due to dysentery. Diarrhoea can cause undernutrition and worsen milder forms of malnutrition. ${ }^{6}$ Diarrhoea is the third leading cause of childhood mortality in India, and is responsible for $13 \%$ of all deaths/year in children under 5 years of age. ${ }^{7}$ Undernutrition contributes for more than a third of under-five deaths. ${ }^{8}$ Young age, low socioeconomic status, poor maternal literacy, birth weight, inadequate breastfeeding, malnutrition, poor sanitation and hygiene practices of the mother, presence of under-five sibling in the family are associated with a higher incidence of diarrheal diseases in young children. Children belonging to poor socio-economic status had a higher diarrheal incidence than the better socio-economic groups because of many factors like unsafe water, poor sanitation and poor foodhygiene.

This study was conducted to determine the prevalence of at-risk under-five children, and to identify and quantify the effects of different factors affecting them.

\section{METHODS}

A cross-sectional observational study was conducted in Urban Training Health Centre of Katihar medical college, Katihar, Bihar, for 2 months from Feb- 2018 to April- 2018, to identify prevalence of at-risk under five children and associated demographic, socio-economic and environmental factors. Sample size taken was 300. By systematic sampling method every $14^{\text {th }}$ house was selected for the study. A predesigned, pre-tested study schedule was used to collect data in which both open and close ended questions were included. Privacy and confidentiality were maintained for mothers of under-five children under present study. Anthropometric and clinical examinations of these children were performed to assess the risk factors under study. Shakir's Tape was used to measure mid-arm circumference and Salter's scale for weight. All the data were collected and analysed using Microsoft Excel and EPI Info software 3.4.3. Results were calculated using percentages.

\section{RESULTS}

\begin{tabular}{|c|c|c|}
\hline & Frequency & Percent \\
\hline \multicolumn{3}{|c|}{ Education of the Father } \\
\hline Illiterate & 36 & 18.0 \\
\hline Primary school & 24 & 8.0 \\
\hline Middle school & 48 & 16.0 \\
\hline High School & 104 & 34.7 \\
\hline Intermediate & 34 & 11.3 \\
\hline Degree \&Above & 36 & 12.0 \\
\hline \multicolumn{3}{|c|}{ Education of the Mother } \\
\hline Illiterate & 90 & 30.0 \\
\hline Primary school & 38 & 12.7 \\
\hline Middle school & 46 & 15.3 \\
\hline High School & 84 & 28.0 \\
\hline Intermediate & 24 & 8.0 \\
\hline Degree \&Above & 18 & 6.0 \\
\hline \multicolumn{3}{|c|}{ Occupation of the Mother } \\
\hline Housewife & 190 & 64.0 \\
\hline Daily wager & 92 & 30.0 \\
\hline Vegetable seller & 4 & 1.3 \\
\hline Tailor & 10 & 3.3 \\
\hline Teacher & 02 & 0.7 \\
\hline Engineer & 02 & 0.7 \\
\hline \multicolumn{3}{|c|}{ Type of Family } \\
\hline Nuclear & 152 & 50.7 \\
\hline Joint & 148 & 49.3 \\
\hline \multicolumn{3}{|c|}{ Religion } \\
\hline Hindu & 166 & 55.3 \\
\hline Muslim & 64 & 21.3 \\
\hline Christian & 68 & 22.7 \\
\hline Others & 02 & 0.7 \\
\hline \multicolumn{3}{|c|}{ Caste } \\
\hline Upper caste & 86 & 28.6 \\
\hline Backward Caste & 122 & 40.7 \\
\hline SC \& ST & 92 & 30.7 \\
\hline \multicolumn{3}{|c|}{ Housing } \\
\hline Kutcha & 22 & 7.3 \\
\hline Pucca & 278 & 92.7 \\
\hline \multicolumn{3}{|c|}{ Socio- Economic Status } \\
\hline Lower Class & 30 & 10.0 \\
\hline Middle Class & 268 & 89.3 \\
\hline Upper Class & 02 & 0.7 \\
\hline
\end{tabular}




\section{Socio-Demographic Profile (Table 1)}

In our present study, thirty percent mothers were illiterate and about $60 \%$ of the fathers were having school level education. About $64 \%$ of the mothers were house-wives and $30 \%$ were on daily wages. Mostly mothers (about $86 \%$ ) were aged between 20-29 years. More than half of the respondents were Hindus. Two thirds (about 64\%) of the study subjects were having family size of less than (or equal to) five members, and nearly half were living in nuclear families. Two thirds of under five children in our study were living in pucca houses.

\section{Under Five Children \& Infections (Table 2)}

In our present study, about $95 \%$ children were of the birth order one or two. About sixteen percent of these children were having birth weight less than 2.5 kilograms. Most of the deliveries (94\%) in our study were institutional. About 39\% of the mothers were having history of caesarean section. Breast feeding was universal in our study village (about 95\%). Nearly 70\% under-five children suffered from respiratory infections, but only $13 \%$ suffered from at least one episode of gastro-intestinal infection during past one year

\begin{tabular}{|c|c|c|}
\hline & Frequency & Percent \\
\hline \multicolumn{3}{|c|}{ Birth Order } \\
\hline 1 & 144 & 48.0 \\
\hline 2 & 140 & 46.7 \\
\hline 3 & 12 & 4.0 \\
\hline 4 & 04 & 1.3 \\
\hline \multicolumn{3}{|c|}{ Birth Weight (in Kilograms) } \\
\hline$>3.2$ & 54 & 18.1 \\
\hline $2.5-3.2$ & 196 & 65.2 \\
\hline $2-2.49$ & 46 & 15.4 \\
\hline$<2$ & 04 & 1.3 \\
\hline \multicolumn{3}{|c|}{ Place of Delivery } \\
\hline Institutional & 282 & 94.0 \\
\hline Home & 18 & 6.0 \\
\hline \multicolumn{3}{|c|}{ Delivery Method } \\
\hline Normal Delivery & 184 & 61.3 \\
\hline Caesarean Section & 116 & 38.7 \\
\hline \multicolumn{3}{|c|}{ Type of Feeding } \\
\hline Breast milk & 284 & 94.7 \\
\hline Artificial Feeds & 12 & 4.0 \\
\hline Both & 04 & 1.3 \\
\hline \multicolumn{3}{|c|}{ Time taken to Start Breast Feeding } \\
\hline$<1 / 2$ Hour & 38 & 12.7 \\
\hline $1 / 2-1$ Hour & 74 & 24.7 \\
\hline$<1-3$ Hours & 120 & 40.0 \\
\hline$>3-6$ Hours & 42 & 14.0 \\
\hline After 6 Hours-1Day & 02 & 0.7 \\
\hline$>1$ day & 12 & 4.0 \\
\hline Not given & 12 & 4.0 \\
\hline \multicolumn{3}{|c|}{ Recurrent ARI in Last 1 Year } \\
\hline No Episodes & 94 & 31.3 \\
\hline$\leq 3$ Episodes & 182 & 60.7 \\
\hline$>3-5$ Episodes & 20 & 6.7 \\
\hline$>5$ Episodes & 04 & 1.3 \\
\hline \multicolumn{3}{|c|}{ Gastrointestinal Infections in Last 1 Year } \\
\hline No Episode & 248 & 82.7 \\
\hline 1 Episode & 40 & 13.3 \\
\hline 2 Episodes & 08 & 2.7 \\
\hline$\geq 3$ Episodes & 04 & 1.3 \\
\hline \multicolumn{3}{|c|}{ Table 2. Profile of the Under-Five Child $(n=300)$} \\
\hline
\end{tabular}

\section{Nutritional Status (Table $3 \& 4$ )}

In our present study, one third of the under-five children were having mild to moderate malnutrition, and severe malnutrition were observed in $16 \%$ children. Nearly one- thirds $(34.7 \%)$ under five children were above $100 \%$ of the reference standard, and $6.8 \%$ below $70 \%$.

\begin{tabular}{|c|c|c|}
\hline & Frequency & Percent \\
\hline Normal & 152 & 50.7 \\
\hline Mild to Moderate Malnutrition & 100 & 33.3 \\
\hline Severely Malnutrition & 48 & 16.0 \\
\hline Table 3. Nutritional Status based upon Mid- Upper Arm \\
Circumference (n=300)
\end{tabular}

\begin{tabular}{|c|c|c|}
\hline Weight for Age & Frequency & Percent \\
\hline$<70 \%$ & 20 & 6.8 \\
\hline $71-80 \%$ & 40 & 13.6 \\
\hline $81-90 \%$ & 51 & 17.0 \\
\hline $91-100 \%$ & 84 & 27.9 \\
\hline$>100 \%$ & 104 & 34.7 \\
\hline \multicolumn{2}{|c|}{ Table 4. Nutritional Status Based upon Weight for Age (n=300) } \\
\hline
\end{tabular}

\section{Prevalence of 'At-Risk' Factors (Table 5)}

Our present study shows that about sixty-three percent of the under-five children are at-risk for two or more factors.

\begin{tabular}{|c|c|c|}
\hline & Frequency & Percent \\
\hline No Risk factor & 72 & 24.0 \\
\hline 1 Risk factor & 38 & 12.7 \\
\hline 2 Risk factors & 120 & 39.3 \\
\hline 3 Risk factors & 54 & 18.0 \\
\hline >3 Risk factors & 18 & 6.0 \\
\hline \multicolumn{2}{|c|}{ Table 5. Risk Factor Prevalence (n=300) } \\
\hline
\end{tabular}

\section{DISCUSSION}

In our study, literacy of the fathers of under-five children were high $(82 \%)$, as compared to their mothers (60\%). Mittal A, et $\mathrm{al}^{7}$ found $70.75 \%$ literacy rate in Patiala, Punjab. There was a significant association between educational status of parents and the number of 'at-risk' children. It was seen that the number of 'at-risk' children decreases with the increased level of education of parents. Maternal primary education has direct impact on child mortality. Mondal et $\mathrm{al}^{9}$ in his study found risk of child mortality decreased with increased female education. Majority of the families belonged lower class. Aswar et $\mathrm{al}^{10}$ in their study found that statistically significant association was present between at-risk children and poverty. Wagstaff A. ${ }^{11}$ et al shown that low socio-economic families are at more risk of childhood morbidities, because of poor sanitation facilities and practices available in these families. In a 2016 publication that examined how specific diseases and injuries are affected by environmental risk, the WHO estimated that $23 \%$ of all deaths and $26 \%$ of deaths among children $<5$ years of age were due to modifiable environmental factors: some 1.7 million children die every year from causes related to unhealthy environments, including the more than $3,60,000$ deaths stemming from a lack of access to clean water and sanitation.

Nearly $70 \%$ of the under-five children suffered from respiratory infections, but only $13 \%$ of them suffered from gastro-intestinal infection during the past one year. Housing has strong association with infections. A properly ventilated house is protective against many respiratory infections. Sharma et al, found that housing, overcrowding and ventilation were significantly associated with respiratory and gastro-intestinal infections in under-five children.

In our present study, one third of the under-five children were having mild to moderate malnutrition, and severe 
malnutrition were observed in $16 \%$ of study subjects. Nearly $6.8 \%$ of the under-five children were below $70 \%$ of the reference standard. Aswar et $\mathrm{al}^{10}$ and Bhasin et al,12 in their study also found weight for age less than $70 \%$ as the most common risk factor in their respective studies, i.e., $39 \%$ and $40.5 \%$ respectively. Jelliffe concluded from his study that diarrhoea may be an important contributing factor leading to malnutrition.

\section{CONCLUSIONS}

All risk factors for under-five children should be identified and health workers, especially in rural areas should be trained properly, so that we can deliver better services. There should be special provisions of health care facilities for under-five children. Proper training of health care providers and education- and communication-campaigns are need of the hour to decrease the infant morbidity and mortality.

\section{Recommendations}

There is an urgent need for enhancement of staff competence and providing necessary logistic support. The detailed criteria for screening children, especially under-five, 'at-risk' should be developed, agreed and disseminated among the health care providers for early diagnosis, treatment and specialized care.

\section{REFERENCES}

[1] Sample Registration System. Statistical Report 2007, Report No. 2 of 2008, Ministry of Home Affairs, New Delhi. Government of India (2008).
[2] Avachat SS, Phalke VD, Phalke DB. Epidemiological correlates of under-five children at risk: a study in the field practice area of rural medical college, Loni. Health and Population: Perspectives and Issues 2009;32(2):737.

[3] Sharma S, Gupta BP. Prevalence of 'at-risk' under-five children in a rural area. Indian J Community Med 2005;30(1):30.

[4] Wardlaw T, You D. Levels and trends in child mortality. UNICEF/ WHO Report 2011.

[5] Giri VC, Dhage VR, Zodpey SP, et al. Prevalence and pattern of childhood morbidity in a tribal area of Maharashtra. Indian J Public Health 2008;52(4):207-9.

[6] Who Expert Committee. Risk approach for maternal and child health care: WHO Geneva, Offset Publication, 1978: p. 39.

[7] Mittal A, Singh J, Ahluwalia SK. Effect of maternal factors on nutritional status of 1-5 year old children in urban slum population. Indian J Community Med 2007;32(4):264-7.

[8] National Family Health Survey - 3, 2005-2006, Ministry of Health and Family Welfare, Government of India.

[9] Mondal MNI, Hossain MK, Ali MK. Factors influencing infant and child mortality. A case study of Rajshahi district, Bangladesh. J Hum Ecol 2009;26(1):31-9.

[10] Aswar NR, Hiwarkar PA, Kalpana MK. Study of 'at-risk' factors in rural under-five children. Indian J Med Sci 1998;52(10):438-41.

[11] Jha SK, Mishra CP, Hussain MA. Determinants of low birth weight findings from a community based study in a rural area of Varanasi. Indian J Community Health 2009;21(1):18-22.

[12] Bhasin SK, Pandit K, Kapil U, et al. Prevalence of 'at-risk' factors in under-five children. Indian Paediatrics 1994;31:1537-9. 